\title{
On the issue of corrosion in the operation of oil and gas wells
}

\author{
Svetlana Luibimova $^{1 *}$, Lilia Khuzina $^{1}$ \\ ${ }^{1}$ Almetyevsk State Oil Institute, 423450 Almetyevsk, Russia
}

\begin{abstract}
The problem of leakage production strings in production and injection wells is becoming more and more urgent every year in Russia's fields. As a result, the water encroachment of produced products increases, and as a result, the operation of wells becomes unprofitable. The main reasons for the leakage of wells are aging of well stock, poor quality cementation during final works during drilling, corrosion processes in places where aquifers come into contact with the string, killing of wells at pressures higher than the pressure of pressing, depressurization in coupling joints, metal corrosion and other technological reasons. Identification of factors affecting the deformation of production strings in the process of well corrosion is necessary and important, as it is taken into account in the development of measures to increase the accident-free operation of wells. 725 wells of PJSC TATNEFT were analyzed in this work. The analysis revealed that one of the reasons for the corrosion of production strings is the presence of lost circulation horizons, which confirms the analysis.
\end{abstract}

Today, Russia's oil fields are at a late stage of development and, as a result, are characterized by a high and constantly increasing water cut of production. The leakage of production strings is one of the sources of high water cut. The main causes of leakages strings are aging of well stock, poor quality cementation during final works during drilling, corrosion processes in places of contact of aquifers with the string, killing of wells at pressures above the pressure of pressing, depressurization in coupling joints, metal corrosion and other technological reasons [1].

The occurrence of leakage of production strings is connected both with the quality of primary cementing and with various conditions of well operation. To solve the problem of production string leakages different technologies are used with the use of plugging compounds and technical means, each of which has its advantages and disadvantages, its application field. That's why revealing the factors influencing the appearance of production string disturbances as a result of corrosive action is an urgent task that allows reducing accident-free operation of oil and gas wells [1,2].

The causes of irregularities in the service of production strings can be classified as causes:

- related to the peculiarities of the geological structure and properties of the well-column;

- related to the technological processes carried out at the well starting from the construction stage.

Depending on the operating conditions, several negative factors affect the life of production strings casing to a certain extent, which can be attributed to three main processes:
1. External corrosion (poor quality cementing or low cement of cement behind the service life of the operating string, aggressive formation water, wellbore curvature set rate higher than allowed, stray current corrosion from high-voltage power lines and cathodic protection units, etc.);

2. Internal corrosion (aggressiveness of injection agent, wellbore curvature set rate is higher than the allowable value, the high working pressure of the medium in injection wells, etc.);

3. Mechanical wear and a tear of the service life of the operating string (casing abrasion during lowering and lifting operations). Casing abrasion with the formation of through-body rupture is mainly connected with pitting corrosion.

This process takes place in a relatively short time while maintaining the strength of the rest of the casing. Although in some cases there is general corrosion damage with individual ulcers on the surface of the casing.

The efficiency of casing corrosion protection with a cement cycle is between 67 and $98 \%$. Absence of a cement ring behind the production string activates corrosion processes of pipes, interlayer flows of liquid and gas leads to violation of tightness of threaded connections of the string, displacement of the production string. In order to reveal the factors influencing the production strings disturbance, 725 wells were analyzed, 660 of them are operated by Devon, 65 wells - by carbon.

According to the results of the performed analysis were determined [3]:

\footnotetext{
* Corresponding author: lubimova-83@mail.ru
} 
- horizons (tiers), where deformations are most often encountered (Fig.1);

- the extent of production string disturbances (Table 1);

- the average age of well before the first production string deformation (Fig.2);

- technologies used to eliminate strings deformations (fig.3);

- average time of well operation after the elimination of production string leakage (fig.4).

As a result of the analysis of operating strings deformations, it has been determined which (horizons) platforms of the stratigraphic well column is the most frequently encountered.

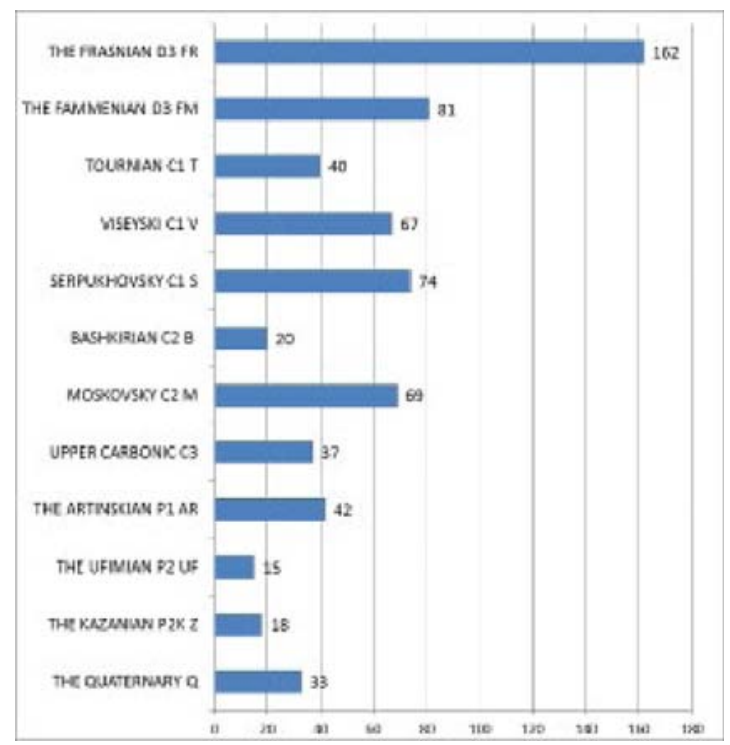

Fig.1. Frequency of deformations in production strings for stratigraphic well column platforms of PJSC TATNEFT.

It can be seen from Fig.1 that deformations of leakage most often occur in the Serpukhov-Oka, Phamena and Frankish platforms. In the researches carried out earlier, it was found out that exactly in these platforms in the process of well construction there were observed absorption of drilling mud, connected with geological heterogeneity, which subsequently led to the destruction of the cement cycle with formation fluids. $[3,4]$

Further, the analysis was carried out on the range of deformations in production strings (Table 1).

Table 1. Range of deformations in production strings in the analyzed NGDU.

\begin{tabular}{|c|c|c|c|}
\hline $\begin{array}{c}\text { Range of } \\
\text { deformations, in } \\
\text { meters }\end{array}$ & $\begin{array}{c}\text { NGDU } \\
\text { AN }\end{array}$ & $\begin{array}{c}\text { NGDU } \\
\text { EN }\end{array}$ & $\begin{array}{c}\text { NGDU } \\
\text { YaN }\end{array}$ \\
\cline { 2 - 4 } & \multicolumn{3}{|c|}{ number of deformations } \\
\hline up to 5 & 436 & 189 & 35 \\
\hline from 5 to 10 & 338 & 27 & 3 \\
\hline from 10 to 20 & 10 & 15 & - \\
\hline from 20 to 30 & 5 & 13 & - \\
\hline from 30 to 40 & 2 & 6 & - \\
\hline from 40 to 50 & 5 & 8 & - \\
\hline from 50 to 100 & 1 & 12 & 1 \\
\hline from 100 to 200 & 1 & 7 & - \\
\hline
\end{tabular}

\begin{tabular}{|c|c|c|c|}
\hline from 200 to 300 & - & 13 & - \\
\hline from 300 to 400 & - & 2 & - \\
\hline from 400 to 500 & 2 & 7 & - \\
\hline from 500 and more & 3 & - & - \\
\hline
\end{tabular}

It can be seen from Table 1 that the most common are deformations with the range from 0 to $10 \mathrm{~m}$. The time of well operation before the first leakage appears is of practical importance in terms of planning the required amount of string and materials for casing string sealing. As a result of the analysis, the average age of the well before the first leakage of production strings deformation has been determined.

Figure 2. shows that in wells drilled in 1960-1970 the first production strings deformation occurs in 38 years, and in subsequent groups, there is a tendency to decrease the operating period before the first deformation of production strings

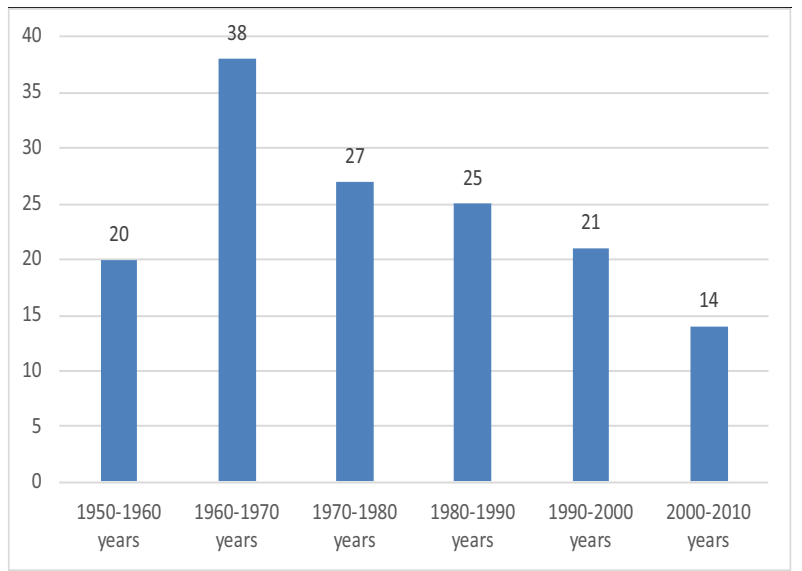

Fig.2. The average age of the well at the first occurrence deformation in production strings on PJSC TATNEFT.

Further, the methods used to eliminate deformations, drilled wells NGDU for 1950-2010 were analyzed. From the given graph (fig.3) it is visible, that elimination of leakages was most often reached by means of tamping that is partially connected with the range of deformation from 0 to $10 \mathrm{~m}$, and also with the subsequent occurrence of the methods based on the application of metal patches.

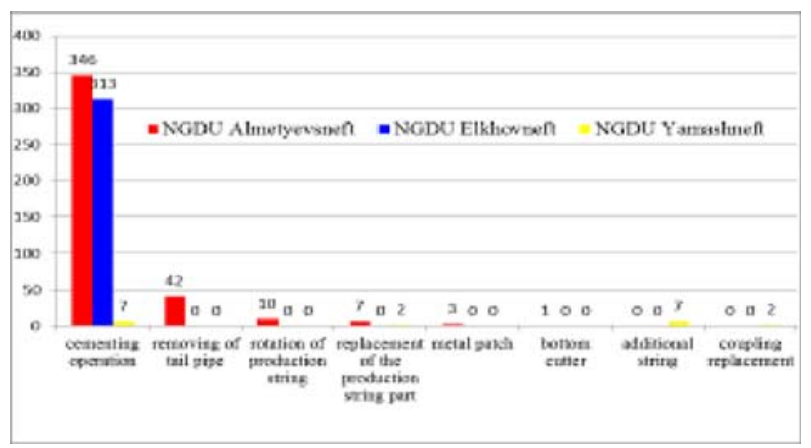

Fig. 3. Quantity by types of applied technologies to eliminate deformations in production strings on PJSC TATNEFT.

The application of a particular technology to eliminate leakage depends on the nature of the deformation (holes, corrosion, longitudinal cracks, etc.). For example, in case of a corrosion violation, the sealing 
of production strings is mainly performed with a metal plaster (a radial tailpipe, installation of casing patch, profile packer). In addition to methods to eliminate leakages of strings, methods to isolate leakages are also practiced. For this purpose, different packers or a double packer system are used.

The selection or application of a specific method of technology to eliminate production string leakage should ensure subsequent long-term operation of the well, which is a criterion for assessing the success of this technology. An important factor of the applied technology is the average time of well operation after the restoration of tightness before the subsequent leakage. Well operation time from the first to the second leak is shown in the graph (Fig. 4).

From the given data it is possible to conclude that the most effective technologies for liquidation of deformations are installation of the metal patch, running in of additional string and cementing [4].

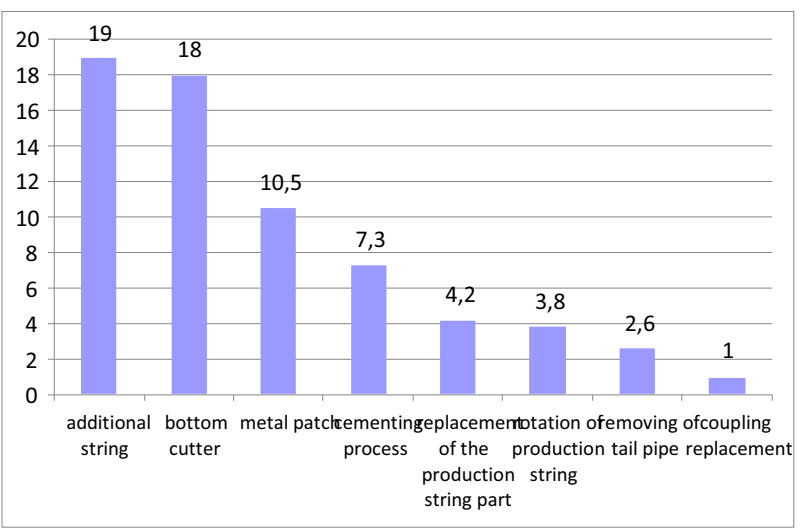

Fig.4. Well operation time from the first to repeated deformation.

\section{Conclusions:}

1. $50 \%$ of deformation of production string leakage occurred in the Serpukhov-Oka, Phamena and Frankish platforms in PJSC TATNEFT at the oilfields of NGDU Almetyevneft, NGDU Elkhovneft, NGDU Yamashneft which are caused by the destruction of the cement ring with contacting formation fluids. In the researches carried out earlier, it was found out that exactly in these tiers in the process of well construction there were observed absorption of drilling mud connected with geological heterogeneity. Thus, the dependence of leakages of production strings on lost circulation horizons as revealed, the quality isolation of which during well drilling will prevent a large number of deformations [5].

2. For a group of wells drilled during the period 1960-1970 the first deformations of production strings are observed in 38 years. At this time in drilling enterprises there appeared serially produced hydraulicmechanical packers with opening connection and strict requirements on the quality of isolation of zones of flushing fluid absorption before launching production string. For the following groups, there is a tendency to decrease the operating period before the first disturbance of production strings. So, for a group of wells drilled in 1970-1980 the first deformations are observed in 27 years, for a group of wells drilled in 1980-1990 - in 25 years, for a group of wells drilled in 1990-2000 - in 21 years, for a group of wells drilled in 2000-2010 - in 14 years $[5,6]$.

3. Cementing is the most frequently used methods for elimination of production string deformations in NGDU Almetyevneft and Elkhovneft, and cementing and running-in additional string in NGDU Yamashneft.

4. In the context of analysis of 725 wells of NGDU Almetyevneft, Elkhovneft and Yamashneft revealed that the most common range of deformation is the interval from 0 to 10 meters. The application of a particular technology to eliminate deformations depends on the nature and extent of the ranges. The most effective technology for the elimination of deformations is cementing, which is connected with the fact that the range of deformations is mainly from 0 to 10 meters. For example, if the range of deformation is from 10 to $20 \mathrm{~m}$, then to eliminate leakage in operating strings packers are used; from 20 to $25 \mathrm{~m}$ - tail pipes; from $50 \mathrm{~m}$ additional strings

5. In the work, it is revealed that one of the reasons for the corrosion of production strings is the presence of lost circulation horizons, which confirms the analysis $[5,6]$.

\section{References}

1. A.F.Slivchenko, S.V.Lyubimova, A.A. Zalyatdinov. The conference proceedings. Far Eastern Federal University. Local sealing technique to improve production string integrity of curdfish, (2019)

2. A.A.Zalyatdinov, L.B.Khuzina, S.V.Lyubimova, R.R.Khuzin. Construction of Oil and Gas Wells on Land and at Sea. Application of profile blockers for protection of an operating column in absorption intervals. 9. 27-29 (2018)

3. L.B.Khuzina, S.V.Lyubimova, A.F.Slivchenko, S.I.Golub, F.Z.Ismagilov. Application of technology to eliminate leakage in production strings on the example of wells NGDU PJSC TATNEFT. Oil industry. 12. 121-123 (2015)

4. Takhautdinov S.F., Slivchenko A.F., Zalyatov M.S. Textbook for students of higher educational institutions studying in the bachelor's degree direction 21.03.01 "Oil and gas business". Technology of oil and gas wells workover. 344 (2014)

5. Khuzina L.B., Lyubimova S.V., Slivchenko A.F., Goluby S.I., Shaikhutdinova A.F., Latypova R.F. Research and Development report. Analysis of the operating column sealing and proposals to improve its efficiency depending on the mining and geological conditions. 42 (2014) 